\title{
Ebeveynlerin Sosyoekonomik Düzeyleri ile Çocuklarının Okul Hayatına Katılımları Arasındaki İlişki
}

\section{The Relationship between Socioeconomic Status of Parents and their Involvement in School Life}

\author{
Uluhan KURT*
}

\author{
Yasemin TAŞ** (iD)
}

Received: 13 October 2018

Research Article

Accepted: 17 June 2019

\begin{abstract}
In this study, it was aimed to investigate the relationship between the socioeconomic status of the parents of middle school students and their involvement in the school life of the child. The study is a correlational study and the data were collected through surveys. With the specified purpose, demographic information questionnaire and parental involvement scale were administered to a sample consisting of 926 students in grade 6 through 8, enrolling in the middle schools in the central districts of Erzurum province. Education level of parents and working status of parents were used as indicators of the socioeconomic status of parents. Parental involvement, on the other hand, was addressed with parents' educational aspiration, parental participation, parental communication, and parental autonomy support. Canonical correlation analysis showed that the education level of the parents and the working status of the father are in a positive relation with the parental involvement in the school life. Based on these findings, it can be said that parents who have high socioeconomic status have a higher aspiration for their children's education, communicate more with their children about school, participate more in activities and meetings in the school, and support more their children's autonomy.
\end{abstract}

Keywords: parental involvement to school life, socioeconimic status, middle school.

ÖZ: Bu araştırmada, ortaokul öğrencilerinin ebeveynlerinin sosyoekonomik düzeyi ile çocuklarının okul hayatına katılımı arasındaki ilişkinin incelenmesi amaçlanmıştır. Çalışma korelasyonal bir çalışma olup, anket yolu ile veriler toplanmıştır. Belirlenen amaç doğrultusunda Erzurum ili merkeze bağlı ilçelerdeki ortaokullarda öğrenim görmekte olan, 6. sınıftan 8. sınıfa kadar toplam 926 öğrenciden oluşan örnekleme, demografik bilgi anketi ve ebeveyn katılımı ölçeği uygulanmıştır. Ebeveynlerin sosyoekonimik düzeyinin göstergeleri olarak anne ve babanın eğitim düzeyi ile çalışma durumu kullanılmıştır. Ebeveynlerin çocuklarının okul hayatına katılımını belirlemek için ise, ebeveynlerin çocuklarının eğitimi ile ilgili arzusu, ebeveyn-çocuk iletişimi, ebeveyn katılımı ve ebeveynlerin özerklik desteğinden yararlanılmıştır. Yapılan Canonical korelasyon analizi sonuçları, ebeveynlerin eğitim düzeyi ve babanın çalışma durumunun, ebeveynlerin okul hayatına katılımı ile pozitif yönde ilişkili olduğunu göstermiştir. Bu sonuçlar doğrultusunda, sosyoekonomik düzeyi yüksek olan ebeveynlerin, çocuklarının eğitimi ile ilgili arzusunun daha yüksek olduğu, çocukları ile okulda olanlar hakkında daha fazla iletişim kurduğu, okuldaki etkinliklere ve toplantılara daha fazla katılım gösterdiği ve çocuklarının özerkliğini daha fazla desteklediği söylenebilir.

Anahtar Kelimeler: ebeveynlerin okul hayatına katılımı, sosyoekonomik düzey, ortaokul.

\footnotetext{
Corresponding Author: Science Teacher, Ministry of National Education, Erzurum, Turkey, uluhaaan@hotmail.com, https://orcid.org/0000-0002-0683-6875

** Asst. Prof. Dr., Atatürk University, Erzurum, Turkey, tasyase@ gmail.com, https://orcid.org/0000-0002-3553-8711
}

Citation Information

Kurt, U., \& Taş, Y., (2019). Ebeveynlerin sosyoekonomik düzeyleri ile çocuklarının okul hayatına katılımı arasındaki ilişki. Kuramsal Eğitimbilim Dergisi [Journal of Theoretical Educational Science], 12(3), 978-991. 


\section{Giriş}

Ebeveyn katılımı; ebeveynlerin okulda gerçekleşen etkinliklere (toplantı, sportif ve akademik etkinlikler vb.) gönüllü olarak ya da kendilerine görev addederek katılım sergilemesi, çocuğunun eğitimi ile ilgili arzulu olması, okul ve evdeki belirli etkinliklere aktif olarak katılması ve okuldaki görevli personel ile sürekli iletişimde bulunması gibi çeşitli şekillerde ifade edilmektedir (Demircan, 2012; Grolnick \& Slowiaczek, 1994; Hong \& Ho, 2005; Patrikakou 2008). Ebeveyn katılımı, eğitim öğretim sürecinde önemli bir rol oynamaktadır (Jeynes, 2007). Örneğin çalışmalar, ebeveyn katılımının öğrencinin ders başarısını olumlu yönde etkilediğini (Fan \& Chen, 2001; Jeynes, 2003; Shaver \& Walls, 1998) ve çocukların sosyal, davranışal ve duygusal gelişimlerine katkı sağladığını belirtmektedir (Desimone, 1999; Pelletier \& Brent, 2002).

İlgili alanyazında ebeveyn katılımı iki farklı yapıda ele alınmaktadır. Bunlar, ebeveyn tarafından başlatılan katılım ev temelli katılım ve okul tarafindan başlatılan okul temelli katılımdır. Ev temelli katılımda öğrencinin ev ödevlerine ebeveynlerin katkısı ve ev içinde çocuğun sergilemesi gereken davranışlar ele alınırken; okul temelli katılımda okul-aile işbirliği, iletişimi ve ailenin okulda gerçekleşen faaliyetlere katılımı ele alınmaktadır (Driessen, Smit, \& Sleegers, 2005). Yukarıdaki iki unsura ilaveten okul temelli katılıma, ebeveynlerin çocuğunun sınıfına ziyaretler yapması ve okulda gerçekleştirilen faaliyetlere katılması sayılabilir (Abbak, 2008). Burada ev temelli katılım hususunda oldukça önem atfedilen durumlardan birisi, ebeveynlerin çocuğunun ev ödevlerine yardımcı olmasıdır. Ebeveynlerin çocuğunun ödevlerine yardımcı olması ve onunla birlikte çalışması için ebeveynlerin derslerle ilgili üst düzey akademik bilgilerinin olmasına gerek yoktur. Zira ailelerin bu etkinliğindeki asıl amaç, çocuğunun yanında olduğunu ve çocuğunun eğitimine verdiği önemi çocuğuna hissettirmesidir (Şahin \& Aral, 2012). Ebeveyn katılımındaki bir diğer husus da ailenin çocuğuna olan özerklik desteğidir. Özerklik desteği, çocuğun kendi başına başarılı olabileceği eylemlerde ebeveynlerin müdahale etmemesi ve çocuğun kendi seçimlerine destek olmasıdır (Özdemir \& Çok, 2011).

Ebeveynlerin okul hayatına katılımını oluşturan bir diğer faktör ise ebeveynlerin çocuğunun eğitimi ile ilgili arzusudur. Ebeveynlerin çocuğunun eğitimi ile ilgili arzusu, onların çocuğun eğitimine verdiği destek ve çocuğun eğitim hayatından beklentisi olarak tanımlanabilir (Fan \& Williams, 2010). Ebeveynlerin çocuğun eğitimi ile ilgili arzusunun yüksek olması, çocuğun akademik başarısı üzerinde olumlu katk1 sağlamaktadır (Fan, 2001). Ayrıca, ebeveynlerin çocuğu ile iletişimi, ebeveynler ile çocuk arasındaki ilişkilerin şekillenmesine imkan vermektedir (Çalışkan \& Aslanderen, 2014). Bu noktada ailelere, demokratik bir ev ortamı oluşturmak için çocukları ile olan iletişiminde baskıcı ve sürekli kural koyucu olmaktan kaçınmaları, çocuğun düşüncelerini ve önerilerini önemsemeleri tavsiye edilmektedir (Barbato, Graham \& Perse, 2003). Böyle bir ortam oluşturulduğunda, çocuk kendisini değerli hissedecek ve benlik saygısı artacaktır (Çağdaş, 2002). Aksi takdirde, çocuk iletişim kurarken, kendisinin birey olarak kabul edilmediğini ve görüşlerinin dikkate alınmadığını düşünecektir. Bu durumun sonucu olarak kuşak çatışmasının başlaması kaçınılmaz hale gelecektir (Kocaman, 2006).

Çocuğun okul hayatı boyunca önem arz eden ebeveyn katılımı, bir takım sosyopolitik faktörlerden etkilenmektedir. Bunlar arasında ailenin sosyoekonomik statüsü 
(ebeveynlerin çalışma durumu, eğitim düzeyleri vb.) ve ailenin geçmişte yaşamış olduğu olumsuz okul deneyimleri gibi faktörler sayılabilir (LaRocque, Kleiman, \& Darling, 2011). Özellikle ebeveynlerin okul hayatına katılımı ile sosyoekonomik düzeyi arasındaki ilişkiyi inceleyen bir takım çalışmaların varlığı dikkat çekmektedir (Baeck, 2010; Lee \& Bowen, 2006; Lueptow, 1975; Reay, 2004; Sui-Chu \& Willms, 1996; Vellymalay, 2012). Ebeveynlerin sosyoekonomik düzeyinin göstergeleri arasında, ebeveynlerin iş durumu ve eğitim durumu sayılabilir. Ebeveynlerin sosyoekonomik düzeyi ile okul hayatına katılımı arasında yakın ilişkiler olduğunu ortaya koyan çalışmalar vardır (Astone \& McLanahan, 1991; Heyns \& Catsambis, 1986; Milne, Myers, Rosenthal, \& Ginsburg, 1986). Örnegin, ön lisans ve daha üzeri eğitim düzeyine sahip olan ebeveynlerin, kısıtlı zamana sahip olmalarına rağmen, çocukları ile eğitimleri hakkında konuşma, çocuklarının eğitimleri ile ilgili aktivite ve toplantılara katılma, çocuklarının eğitiminde başarı beklentisi içerisinde olma gibi daha fazla katılım gösterdikleri; buna karşılık eğitim düzeyi düşük olan ebeveynlerin ise daha az katılım gösterdikleri gözlenmiştir (Lee \& Bowen, 2006). Diğer bir ifadeyle ebeveynlerin eğitim düzeyi ile çocuklarının eğitimine katılımı arasında pozitif bir ilişkinin varlığından bahsedilebilir. Bu durum, yüksek eğitimli ailelerin çocuğunun eğitimsel ihtiyaçlarını daha iyi anladığına ve bunun da ailelerin çocuğunun eğitim sürecinde zorlanabileceği kısımları önceden tahmin edip zorlukların üstesinden gelmede çocuklarına daha fazla yardımcı olduklarına işaret etmektedir (Epstein, 2001). Eğitim seviyesi düşük olan ebeveynlerin katılım isteğini düşüren etkenler arasında çocuğun ev ödevleri ve diğer okul-aile arasındaki konular hakkında sınırlı bilgi birikimine sahip olma ve öz-güven eksikliği yaşamaları sayılabilir (Barnard, 2004; Pena, 2000).

Ailenin sosyoekonomik düzeyi ile ilgili faktörlerin ebeveynlerin katılımına etki ettiği, yurt dışında yapılan bir çok çalışmada gösterilmiştir (Baeck, 2010; Crozier, 1999; Jafarov, 2015; Jordan, Orozco, \& Averett, 2001; Kung, 2016; Lee \& Bowen, 2006; Pena, 2000; Potvin, Deslandes, \& Lecrec, 1999). Örneğin Kung (2016), sosyoekonomik statünün ebeveynlerin katılımına doğrudan ya da dolaylı etki ettiğini ve yüksek sosyoekonomik statüye sahip ebeveynlerin çocuklarına psikolojik destek, gözlem yapma, yardımcı olma, kaynak oluşturma vb. faktörler açısından daha fazla destek sağladığını bulmuşlardır. Pena (2000) ise yaptığı çalışmada düşük eğitim düzeyine sahip ebeveynlerin, yüksek eğitim düzeyine sahip ebeveynlere göre, okullarda yapılan aktivitelere daha az katılım gösterme eğiliminde olduğunu göstermiştir.

Özetle, yapılan çalışmalar başta ebeveynlerin eğitim durumu olmak üzere hane geliri ve iş statüsü daha yüksek olan aileler, çocuklarının okul hayatına daha fazla katılım gösterme eğiliminde olduğunu göstermektedir (Baker \& Stevenson, 1986; Balli, Demo \& Wedman, 1998; Chu \& Willms, 1996; Katsilis \& Rubinson, 1990; Poston \& Falbo, 1990; Vellymalay, 2012). Bu konu üzerine uluslararası alanyazındaki çokça çalışmaya karşılık, Türkiye'de ailelerin sosyoekonomik düzeyi ile okul hayatına katılımını inceleyen oldukça sınırlı sayıda çalışma bulunmaktadır. Ülkemizde yapılan çalışmalarda ise daha çok sosyoekonomik düzeyin öğrenci başarısı ile olan ilişkisini incelenmiş ve bu değişkenler arasında pozitif ilişki olduğu belirtilmiştir (ör. Gökçe, 2005; Uzun, 2017). Bu çalışmada ise, Erzurum ilindeki ortaokul öğrencilerinin algılarına göre ebeveynlerin okul hayatına katılımı ve sosyoekonomik düzeyi arasındaki ilişkiyi incelemek amaçlanmıştır. Çalışmada ebeveynlerin okul hayatına katılımı; ebeveynlerin çocuklarının eğitimi ile ilgili arzusu, ebeveyn-çocuk iletişimi, ebeveyn 
katılımı ve ebeveynlerin özerklik desteği olarak dört boyutta ele alınmıştır. Ailelerin sosyoekonomik düzeyi ise ebeveynlerin eğitim düzeyi ile çalışma durumları yardımıyla belirlenmiştir. Çalışma sonuçları, Erzurum'daki ortaokullarda öğrenim gören ögrencilerin ailelerinin sosyoekonomik düzeyi ve okul hayatına katılımı arasındaki ilişkiyi anlamaya yardımcı olacağı düşünülmektedir. Böylece bu çalışmada elde edilecek sonuçların, ebeveynlerin eğitim düzeyi ile çalışma durumlarının, ebeveynlerin çocuklarının eğitimi ile ilgili arzusu, ebeveyn-çocuk iletişimi, ebeveyn katılımı ve ebeveynlerin özerklik desteği ile ilişkisinin ortaya çıkarılma noktasında ilgili alan yazına katkı sağlayacağı düşünülmektedir.

\section{Yöntem}

$\mathrm{Bu}$ çalışmada, nicel araştırma yaklaşımlarından olan korelasyonel araştırma yöntemi kullanılmıştır. Korelasyonel araştırmalar; iki veya daha fazla değişken arasındaki ilişkinin yönü ve gücünü belirleyen, değişkenlerin birlikte değişimi açısından araştırmacıya bilgiler sunan araştırmalardır (Büyüköztürk, Kılıç-Çakmak, Akgün, Karadeniz, \& Demirel, 2008). Bu çalışma, ebeveynlerin sosyoekonomik düzeyi ile çocuklarının okul hayatına katılımı arasındaki ilişkiyi incelediği için korelasyonel araştırma olarak isimlendirilebilir. Veriler toplanmaya başlamadan önce Erzurum İl Milli Eğitim Müdürlüğü'nden gerekli izinler alınmıştır. Veriler, birinci yazar tarafından toplanmıştır. Uygulanan anketlerde katılımcıların kimliğini açığa çıkaracak herhangi bir soru sorulmayıp, uygulama öncesinde öğrencilerin verecekleri cevapların bilimsel bir araştırma için kullanılacağı ve cevaplarının gizli kalacağı hem anketin üst kısmında yazı ile verilmiş hem de araştırmacı tarafından uygulama esnasında sözel olarak ifade edilmiştir.

\section{Çalıșma Grubu}

Araştırmanın örneklemini, Erzurum ili merkez ilçeleri Yakutiye, Palandöken ve Aziziye'de öğrenim görmekte olan 6., 7. ve 8. sinıfa giden toplam 926 öğrenci oluşturmaktadır. Katılımcıların 415'i (\%44.8) kız, 448'i (\%48.4) ise erkektir. Çalışmaya katılan 63 (\%6.8) öğrenci ise cinsiyetini belirtmemiştir. Öğrenim gördüğü sınıflara göre öğrenci sayıları ise 6. sinıfta 324 (\%35), 7. sınıfta 374 (\%40.4), 8. sinıfta 183 (\%19.8)'tür. 45 (\%4.8) öğrenci ise sınıf düzeyini belirtmemiştir. Çalışmada kolay ulaşılabilir örnekleme yöntemi kullanılmıştır.

\section{Veri Toplama Araçları}

Araştırmada demografik bilgi anketi ve ebeveyn katılımı ölçeği kullanılmıştır.

Demografik bilgi anketi. Katılımcıların kendisi ve ailesi ile ilgili demografik bilgilerin istendiği bu ankette öğrencilerin cinsiyet ve sınıf düzeyinin yanı sıra ebeveynlerin eğitim durumu (hiç okula gitmemiş, ilkokul, ortaokul, lise, üniversite ve lisansüstü) ile çalışma durumunu (çalışmıyor, düzenli bir işi yok, çalışıyor) içeren sorular yöneltilmiştir.

Ebeveyn katılımı ölçeği. Ailelerin okul hayatına katılımını ölçmek için Kurt ve Taş (2018) tarafından Türkçeye uyarlaması yapılan Ebeveyn Katılımı Ölçeği kullanılmıştır. Ölçek dört alt boyuttan oluşmaktadır. Bu boyutlar; ebeveynlerin çocuğun eğitimi ile ilgili arzusu, ebeveyn katılımı, ebeveyn iletişimi ve ebeveyn özerklik 
desteğidir. İlk üç alt boyut, Fan'ın (2001) çalışmasında kullanmış olduğu ölçekten alınmıştır. Ebeveyn özerklik desteği ise ilk olarak Robbins (1994) tarafından kullanılan, daha sonra Niemiec ve diğerlerinin (2006) yapmış oldukları çalışmada geçerlik ve güvenirlik durumunun desteklendiği Ebeveyn Algısı Ölçeği'nden (Perceptions of Parent Scales; POPS) uyarlanmıştır. Türkçeye uyarlama çalışmasında yapılan doğrulayıcı faktör analizi sonuçları $(\mathrm{RMSEA}=0.084, \mathrm{NNFI}=0.981, \mathrm{CFI}=0.984, \mathrm{~S}-\mathrm{RMR}=0.040)$ önerilen faktör yapısını desteklemiş ve yapı geçerliği için delil sağlamıştır (Kurt \& Tas, 2018).

Ebeveyn eğitim arzusu, 2 maddeden oluşup, katılımcıya ebeveynlerinin hangi okul düzeyine kadar ilerlemesini istediği sorulmaktadır. Katılımcı bu soruya 1=Ortaokul, 2= Lise, 3=Ön lisans, 4=Lisans, 5=Lisansüstü eğitim seçenekleri arasından cevap vermesi istenmiştir. Bu çalışmada, ebeveyn eğitim arzusu değişkeni için hesaplanan Cronbach alpha güvenirlik katsayısı .95 'tir.

Ebeveyn iletişimi, 5 maddeden oluşup, çocuğun okuldaki akademik ve sosyal etkinlikler, sınıfta yapılan çalışmalar, lise hayatını planlama gibi konularda ebeveynleriyle konuşmasını içermektedir (örnek madde 1: "Okuldaki akademik etkinlikler (sınavlar, ödevler, ders programı, vb.) hakkında anne-babamla konuşurum”). $\mathrm{Bu}$ alt boyuta ait maddeler 5'li likert tipinde yanıtlanmaktadır (1=Hiçbir zaman, 2=Nadiren, 3=Bazen, 4=Çoğu zaman, 5=Her zaman). Bu çalışmada, ebeveyn iletişimi için Cronbach alpha güvenirlik katsayısı .92 olarak hesaplanmıştır.

Ebeveyn katılımı, 4 maddeden oluşup, ebeveynlerin okulda veya sinıfta gerçekleştirilen etkinliklere katılımı gibi durumları içermektedir (örnek madde 1: "Anne-babam okul toplantılarına katılır") Ölçek maddeleri 5'li likert tipinde yanıtlanmaktadır (1=Hiçbir zaman, 5=Her zaman). Bu çalışmada, ebeveyn katılımı için Cronbach alpha güvenirlik katsayısı .88 'dir.

Ebeveyn özerklik desteği, 6 maddeden oluşup çocuğun algısına göre ebevenylerinin çocuğun düşünce ve görüşlerini dikkate alıp almadığı ya da çocuğunun eylemlerine verdiği tepkileri içermektedir (örnek madde 1: "Anne-babam hata yaptığımda bunu anlayışla karşılar” Ölçek maddeleri 5'li likert tipinde yanıtlanmaktadır (1=Hiçbir zaman, 5=Her zaman). Bu çalışmada, ebeveyn özerklik desteği için Cronbach alpha güvenirlik katsayısı .89 olarak hesaplanmıştır.

\section{Bulgular}

Ebeveynlerin eğitim düzeyleri incelendiğinde (Bkz. Tablo 1), annelerin eğitim durumu için modun ilkokul düzeyinde öğrenime sahip olma, babaların eğitim durumu için ise modun lise düzeyinde öğrenime sahip olma olduğu görülmüştür. Lisans ve lisansüstü eğitimli babaların yüzdesi 19.6 iken bu oran annelerde \%7.7'dir. Babaların annelere göre daha yüksek eğitime sahip olduğu gözükmektedir. 
Tablo 1

Ebeveynlerin Eğitim Düzeyi

\begin{tabular}{ll}
\hline Annenin Eğitim Düzeyi & Frekans (Yüzde) \\
\hline Hiç okula gitmemiş & $92(\% 9.9)$ \\
İlkokul & $337(\% 36.4)$ \\
Ortaokul & $266(\% 28.7)$ \\
Lise & $137(\% 14.8)$ \\
Üniversite & $58(\% 6.3)$ \\
Lisansüstü & $13(\% 1.4)$ \\
\hline Babanın Eğitim Düzeyi & Frekans (Yüzde) \\
\hline Hiç okula gitmemiş & $22(\% 2.4)$ \\
İlkokul & $150(\% 16.2)$ \\
Ortaokul & $264(\% 28.5)$ \\
Lise & $273(\% 29.5)$ \\
Üniversite & $130(\% 14)$ \\
Lisansüstü & $52(\% 5.6)$ \\
\hline
\end{tabular}

Ebeveynlerin çalışma durumu incelendiğinde (Bkz. Tablo 2), annelerin büyük çoğunluğunun (\%85.7) çalışmadığı, babaların ise büyük çoğunluğunun (\%79.4) çalıştığ1 görülmektedir.

Tablo 2

Ebeveynlerin Çalışma Durumları

\begin{tabular}{ll}
\hline Annenin Çalışma Durumu & Frekans (Yüzde) \\
\hline Çalışmıyor & $794(\% 85.7)$ \\
Düzenli bir işi yok & $26(\% 2.8)$ \\
Çalışıyor & $95(\% 10.3)$ \\
Çalışma durumu belirtilmeyen & $11(\% 1.2)$ \\
\hline Babanın Çalı̧̧ma Durumu & Frekans (Yüzde) \\
\hline Çalışsmıyor & $42(\% 4.5)$ \\
Düzenli bir işi yok & $130(\% 14)$ \\
Çalışıyor & $735(\% 79.4)$ \\
Çalışsma durumu belirtilmeyen & $19(\% 2.1)$ \\
\hline
\end{tabular}

Ebeveynlerin okul hayatına katılımına ait alt boyutlara ilişkin betimsel istatistikler Tablo 3 'te verilmiştir. Buna göre ebeveynler, çocuklarının lisans düzeyinde eğitim almalarını istemektedir (ebeveyn eğitim arzusu için $\bar{X}=3.97$ ). Ebeveyn iletişimi $(\bar{X}=3.56)$, ebeveyn katılımı $(\bar{X}=3.35)$ ve ebeveyn özerklik desteği $(\bar{X}=3.50)$ boyutları için ortalama degerler ölçeğin orta noktası olan 3 'ün biraz üzerinde olup ebeveynlerin çocuğunun okul hayatına katılımının orta düzeyde olduğunu göstermektedir. Bu durum 
ebeveynlerin bazen çocuklarının özerkliğini destekleyici davranışlar sergilediğini, bazen okul ve sınıfta gerçekleştirilen faaliyetler hakkında çocukları ile konuştuğunu ve okulda gerçekleştirilen faaliyetlere katıldığını göstermektedir. Ayrıca, ebeveyn özerklik desteği, ebeveyn iletişimi ve ebeveyn katılımına ilişkin ortalama değerlerin birbirine oldukça yakın olduğu görülmektedir.

Tablo 3

Ebeveynin Okul Hayatına Katılımı için Betimsel İstatistikler

\begin{tabular}{lcccccc}
\hline & Ortalama & $S S$ & Min & Max & Çarpıklık & Basıklı \\
\hline Ebeveyn eğitim arzusu & 3.97 & 1.28 & 1 & 5 & -1.21 & .25 \\
Ebeveyn iletişimi & 3.56 & 1.16 & 1 & 5 & -.63 & -.82 \\
Ebeveyn katılımı & 3.35 & 1.11 & 1 & 5 & -.40 & -.98 \\
Ebeveyn özerklik desteği & 3.50 & 1.04 & 1 & 5 & -.79 & -.31 \\
\hline
\end{tabular}

Ebeveynlerin sosyoekonomik statüsü ile çocuğunun okul hayatına katılımı arasındaki ilişkinin belirlenebilmesi için Canonical korelasyon analizi yapılmıştır. Sosyoekonomik statünün göstergeleri olarak; ebeveynlerin çalışma ve eğitim durumu ele alınmıştır. Ebeveynlerin okul hayatına katılımı ise ebeveyn eğitim arzusu, ebeveyn iletişimi, ebeveyn katılımı ve ebeveyn özerklik desteği olarak dört boyutta ele alınmıştır. Birinci canonical korelasyon .44 olup (\%19 ortak varyans) değişken takımları arasında istatistiksel olarak anlamlı bir ilişkinin olduğu tespit edilmiştir (Bkz. Tablo 4). İkinci canonical korelasyon ise istatistiksel olarak anlamlı değildir. Tabachnick ve Fidell'in (2013) tavsiye ettiği .30 kesme noktasına göre, annenin çalışma durumu (.18) dışındaki tüm sosyoekonomik statü değişkenlerinin birinci canonical değişken ile pozitif yönde ilişkisinin olduğu görülmüştür. Ebeveyn katılımı değişkenlerinin alt boyutları olan ebeveyn eğitim arzusu (.82), ebeveyn iletişimi (.92), ebeveyn katılımı (.94) ve ebeveyn özerklik desteği (.87) canonical değişkenle pozitif yönde ilişkilidir. Özetle, ebeveynlerin eğitim düzeyi ile babanın çalışma durumu arttıkça, ebeveynlerin çocuğunun okul hayatına daha fazla katılımda bulunduğu söylenebilir.

Tablo 4

Kanonik Korelasyon

\begin{tabular}{lcc}
\hline & \multicolumn{2}{c}{ Birinci Canonical Değişken } \\
\cline { 2 - 3 } & Korelasyon & Katsayı \\
\hline Sosyoekonomik düzey & & \\
Annenin çalışma durumu & .18 & -.09 \\
Annenin eğitim düzeyi & .86 & .32 \\
Babanın çalışma durumu & .52 & .58 \\
Babanın eğitim düzeyi & .78 & .44 \\
Varyans yüzdesi & 41 & \\
Redundancy & 7 & \\
\hline
\end{tabular}


Okul hayatına katılımı

Ebeveyn eğitim arzusu

Ebeveyn iletişimi

Ebeveyn katılımı

\section{Sonuç ve Tartışma}

$\mathrm{Bu}$ çalışmada, Erzurum ilinde öğrenim görmekte olan ortaokul öğrencilerinin ebeveynlerinin sosyoekonomik düzeyi ile okul hayatına katılımı arasındaki ilişki incelenmiştir. Araştırmada elde edinilen bulgulara göre, ebeveynlerin sosyoekonomik düzeyinin göstergelerinden olan ebeveynlerin eğitim durumu ile okul hayatına katılımı arasında pozitif yönde anlamlı bir ilişki vardır. Sosyoekonomik düzeyin bir diğer göstergesi olan ebeveynlerin çalışma durumlarından annenin çalışma durumu ile okul hayatına katılım arasında bir ilişki bulunmazken, babanın çalışma durumu ile okul hayatına katılım arasında pozitif yönde anlamlı bir ilişkinin olduğu tespit edilmiştir.

Ebeveynlerin sosyoekonomik statüsü ile okul hayatına katılımı arasındaki ilişkiyi inceleyen çalışmalar, bu çalışmada elde edilen sonuçlara benzer bulgular elde etmişlerdir. Örneğin, Balli ve diğerleri (1998) araştırmalarında 6. sınıf öğrencilerinin ebeveynlerinin eğitim düzeyi ile çocuklarının eğitimi ile ilgili arzusu ve çocuklarının ev ödevlerine yardımcı olması arasında bir ilişki tespit etmişlerdir. Eğitim düzeyi yüksek olan ebeveynlerin çocuklarının eğitimi ile ilgili arzusunun daha yüksek olduğu ve çocuklarına ev ödevlerinde yardımcı olduğunu bulmuşlardır. Baker ve Stevenson (1986) ise ortaokul 8. sınıf öğrencilerinin anneleri üzerinde yapmış oldukları çalışmada, eğitim düzeyi yüksek annelerin çocuğunun okul faaliyetleri hakkında daha fazla bilgiye sahip olduğu, çocuğunun eğitimi ile ilgili farkındalık durumunun daha fazla olduğu ve çocuğunun akademik ilerlemelerini daha iyi gözlemlediğini rapor etmişlerdir. Bunun yanı sıra, Paston ve Falbo (1990) çalışmalarında yüksek eğitimli ebeveynlerin çocukları ile sık sık iletişim kurduğu ve çocuğunun okuldaki durumu ile ilgili sürekli etkileşim içerisinde olduğunu belirtmiştir. Ebeveynlerin okul hayatına yüksek katılım göstermesi, öğrencinin performansını da olumlu yönde etkilemektedir (Katsills \& Robinson, 1990; Lueptow, 1975; Wellymalay, 2012). Ayrıca, ebeveynlerin sosyoekonomik düzeyleri arttıkça, çocukların daha iyi akademik davranışlar sergilemesinin yanı sıra eğitime karşı olumlu tutumlar geliştirdiği tespit edilmiştir (Reay, 2004).

Sonuç olarak bu çalışmadan elde edilen bulgular, ebeveynlerin eğitim durumunun yüksek olması ve babanın düzenli bir işinin olmasının, ebeveynlerin okul hayatına katılımı ile pozitif ilişki içinde olduğunu göstermektedir. Sosyoekonomik düzeyi daha yüksek olan ebeveynlerin, çocuklarının eğitimi konusunda daha yüksek arzusunun olduğu, çocuklarıyla okulda neler yaptıkları hakkında daha fazla iletişim içinde olduğu, veli toplantıları gibi etkinliklere daha fazla katıldığı ve çocuğun özerkliğini destekleyici davranışlar sergilediği görülmektedir. 


\section{Öneriler}

Araştırmada elde edilen sonuçlar doğrultusunda, özellikle ailelerin sosyoekonomik düzeylerinin düşük olduğu bölgelerde, ailelerin çocuklarının okul hayatına katılımı konusunda bilgilendirilmesinin faydalı olabileceği düşünülmektedir. Örneğin, çocuğun özerkliğini destekleyebilmek için çocuğun kendi kararlarını alması konusunda destek olmaları, sorumluluğunu yerine getirmediğinde onunla doğru bir biçimde iletişime geçmeleri ve neden böyle yaptığını anlamaya çalışmaları, hata yaptığında ya da başarısız olduğunda çocuğunu nasıl destekleyebilecekleri konusunda bilgilendirilmeleri yararlı olabilir. İleriki çalışmalarda, velilere uzmanlar eşliğinde verilecek bu gibi eğitimlerin etkinliği araştırılabilir ve böylece ebeveynlerin çocuklarının okul hayatına sağlıklı bir şekilde katılımı artırılmaya çalışılabilir. İleriki çalışmalarda, Türkiye'nin farklı bölgelerinde yaşayan farklı sosyoekonomik düzeylere sahip ebeveynlerin çocuklarının okul hayatına katılımı incelenebilir ve bu çalışmada elde edilen sonuçlarla karşılaştırılabilir. Ayrıca ileriki çalışmalarda, farklı sınıf düzeylerindeki öğrenciler (ilkokul ve lise gibi) örneklem olarak seçilebilir ve ele alınan ilişkilerin ortaokul öğrencileri ile benzerlik gösterip göstermediği incelenebilir. 


\section{Summary}

Purpose and Significance: Parental involvement is parents' desire for the child's education, the participation of the parents in the school events such as meetings, sports and academic activities voluntarily or as a duty to them and also certain activities at home, and constant communication with school staff (Demircan, 2012; Grolnick \& Slowiaczek, 1994; Hong \& Ho, 2005; Patrikakou, 2008). Parental involvement is of great importance in the child's school life and is influenced by a number of sociopolitical factors one of which is socioeconomic status (ses) of parents (LaRocque, Kleiman, \& Darling, 2011). The indicators of the ses of parents include working status and educational level of parents. Previous studies showed that the ses of the parents is closely related to the parental involvement (e.g., Astone \& McLanahan, 1991; Heyns \& Catsambis, 1986). Although numerous studies have investigated this relationship in abroad, limited number of studies have examined this issue in Turkey. The aim of the present study is to examine the relationship between the parental involvement and the ses of parents of middle school students living in Erzurum. In this study, parental involvement is addressed with parents' educational aspiration, communication, participation, and autonomy support. If these dimensions are explained briefly; the parents' desire for the education of the child is the support they provide for the child's education and their expectation about the child's education (Fan \& Williams, 2010). Parents' participation is about parents' attending to school activities and visiting classroom where the child is studying (Abbak, 2008). Parents' communication is a sincere communication between the parents and the child (Çalışkan \& Aslanderen, 2014). Parental support for autonomy is about the parents' showing respect to the choice of the child and not intervening in the child's actions that may be successful individually (Özdemir \& Çok, 2011).

Methods: With the aim of examining the relation between parental involvement and parents' ses, this study has a correlational research design. Convenience sampling was used and legal permissions were obtained for administration of surveys. The sample of the study consisted of 926 students in grade 6 through 8, living in Erzurum. 448 of the respondents were male (48.4\%) and $415(44.8 \%)$ were female. $63(6.8 \%)$ students did not indicate their gender. The data collection tools include demographic information survey and parental involvement scale. In the demographic information survey, the participants' gender and class level as well as the educational level and working status of the parents were asked. The parental involvement scale was translated and adapted into Turkish by Kurt and Tas (2018) who conducted confirmatory factor analysis and provided construct validity evidence for the Turkish version of the scale. The scale includes four dimensions: parents' educational aspiration, parental participation, parental communication, and parental autonomy support. The first three subscales were taken from Fan's (2001) study while parental autonomy support was taken from Perceptions of Parent Scales (POPS), (Niemiec et al., 2006; Robbins, 1994). In the present study, Cronbach alpha coefficient for the scores obtained from the dimensions of the scale ranged from .88 to .95 .

Results: The data were firstly examined through descriptive statistics. The mode for mother education level is primary school while it is high school for father education. 
The percentage of mothers who have undergraduate or graduate degree is $7.7 \%$ while it is $19.6 \%$ for fathers. Thus, fathers seem to have higher education level than mothers. The majority of mothers (85.7\%) do not work in any job whereas the majority of fathers (79.4\%) work. When descriptive statistics for the dimensions of parental involvement are examined, the parents want their children to receive education at undergraduate level $(\bar{X}=3.97)$. The mean values for parental communication $(\bar{X}=3.56)$, parental participation $(\bar{X}=3.35)$ and parental autonomy support $(\bar{X}=3.50)$ indicate a moderate level of parental involvement. Then, Canonical correlation analysis was performed to examine the relation between the ses of the parents and their involvement to school life. The indicators of ses was education level and working status of parents while parental involvement included dimensions of parents' educational aspiration, parental participation, parental communication, and parental autonomy support. The first canonical correlation is 0.44 (19\% shared variance) and there is a statistically significant relationship between the variable sets. The second canonical correlation is not statistically significant. According to the .30 cut point recommended by Tabachnick and Fidell (2013), all ses variables except the mothers' working status (.18) are found to be positively correlated with the first canonical variable. The dimensions of parental involvement; parents' educational aspiration (.82), parents' communication (.92), parents' participation (.94), and parents' autonomy support (.87) are positively associated with canonical variable.

Discussion and Conclusions: According to findings obtained from this study, the level of education of the parents and father's working status are significantly and positively related to the parental involvement to school life. The findings of the present study is in line with previous research demonstrating the positive relation between parental involvement and ses of parents (e.g., Balli, Demo, \& Wedman, 1998; Paston \& Falbo, 1990) and extend this association to Turkish sample. Based on the findings of the present study, it can be said that parents with higher ses are more likely to have high aspiration for their children's education, communicate with their children about what they are doing in school, participate in activities such as parent meetings, and support their children's autonomy. In this context, it may be useful to inform parents about the importance of parental involvement, especially in areas where the ses of the families are low. For example, in order to support the child's autonomy, it may be useful to inform parents about how to help the child make his own decisions, communicate correctly with him when he does not fulfill his responsibilities, and to support their child when he makes mistakes. In future studies, the effectiveness of training programs aiming to improve parental involvement can be investigated. Additionally, the involvement of parents who have different ses and who live in different regions of Turkey can be examined and results can be compared with the findings of the present study. 


\section{Kaynakça}

Abbak, B. S. (2008). Okul öncesi eğitim programlarındaki ebeveyn katılımı etkinliklerinin anasınıfi öğretmenleri ve ebeveyn görüşleri açısından incelenmesi (Yayımlanmamış Yüksek Lisans Tezi). Çukurova Üniversitesi. Sosyal Bilimler Enstitüsü. Adana.

Astone, N. M., \& McLanahan, S. S. (1991). Family Structure, Parental Practices and High School Completion. American Sociological Review, 56(3), 318-330.

Baeck, U. K. (2010). Parental involvement practices in formalized home-school cooperation. Scandinavian Journal of Educational Research, 54(6), 549-563.

Barbato, C. A., Graham E. E., \& Perse, E. M. (2003). Communicating in the family: An examination of the relationship of family communication climate and interpersonal communication motives. Journal of Family Communication, 3(3), 123-140.

Baker, D. P., \& Stevenson, D. L. (1986). Mothers' strategies for children's school achievement: Managing the transition to high school. Sociology of Education, 59(3), 156-166.

Balli, S. J., Demo, D. H., \& Wedman, J. E. (1998). Family involvement with children's homework: An intervention in the middle grades. Family Relations, 47(1), 149157.Büyüköztürk, Ş., Kılıç-Çakmak, E., Akgün, Ö.E., Karadeniz, Ş., \& Demirel, F. (2008). Bilimsel araştırma yöntemleri. Ankara: Pegem Akademi.

Crozier, G. (1999). Parental involvement: Who wants it?. International Studies in Sociology of Education, 9(3), 219-238.

Çağdaş, A. (2002). Anne-baba çocuk iletişimi. Ankara: Nobel Yayın Dağıtım.

Çalışkan, N., \& Aslanderen, M. (2014). Aile içi iletişim ve siber yaşam: Teorik bir çözümleme. Ahi Evran Üniversitesi Kırşehir Eğitim Fakültesi Dergisi, 15(2), 263277.

Demircan, H. Ö. (2012). Okul öncesi eğitim kurumlarında gelişimsel uygunluk uygulamaları ve ebeveyn katılımı: Öğretmen ve anne-baba görüşleri (Yayımlanmamış doktora tezi). Ortadoğu Teknik Üniversitesi, Ankara.

Desimone, L. (1999). Linking parent involvement with student achievement: Do race and income matter?. The Journal of Educational Research, 93(1), 11-30.

Driessen, G., Smit, F., \& Sleegers, P. (2005). Parental involvement and educational achievement. British Educational Research Journal, 31(4), 509-532.

Epstein, J. L. (2001). Building bridges of home, school and community: the importance of design. Journal of Education for Students Placed at Risk, 6(1-2), 161-168.

Fan, X. (2001). Parental involvement and students' academic achievement: A growth modeling analysis. Journal of Experimental Education, 70(1), 27-61.

Fan, X., \& Chen, M. (2001). Parental involvement and students' academic achievement: a meta-analysis. Educational Psychology Review, 13(1), 1-22.

Fan, W., \& Williams, C. M. (2010). The effects of parental involvement on students' academic self-efficacy, engagement and intrinsic motivation. Educational Psychology, 30(1), 53-74. 
Gökçe, S. (2005). A structural equation modeling study: Factors related to mathematics and geometry achievement across grade levels (Yayımlanmamış Yüksek Lisans Tezi). Ortadoğu Teknik Üniversitesi, Ankara.

Grolnick, W. S., \& Slowiaczek, M. L. (1994). Parents' involvement in children's schooling: A multidimensional conceptualization and motivational model. Child Development, 64, 237-252.

Heyns, B., \& Catsambis, S. (1986). Mother's employment and children's achievement: A critique. Sociology of Education, 59(3), 140-151.

Hong, S., \& Ho, H.Z. (2005). Direct and indirect longitudinal effects of parental involvement on student achievement: Second-order latent growth modeling across ethnic groups. Journal of Educational Psychology, 97(1), 32-42.

Jafarov, J. (2015). Factors affecting parental involvement in education: The analysis of literature. Khazar Journal of Humanities and Social Sciences, 18, 35-44.

Jeynes, W. H. (2003). A meta-analysis: the effects of parental involvement on minority children's academic achievement, Education and Urban Society, 35(2), 202-218.

Jeynes, W. H. (2007). The relationship between parental involvement and urban secondary school student academic achievement: a meta-analysis. Urban Education, 42(1), 82-110.

Jordan, C., Orozco, E., \& Averett, A. (2001) Emerging issues in school, family, \& community connections: Annual synthesis. Austin, TX: Southwest Educational Development Lab.

Katsilis, J., \& Rubinson, R. (1990). Cultural capital, student achievement, and educational reproduction: The case of Greece. American Sociological Review, 55(2), 270-278.

Kocaman, V. (2006). Çocuklarda iletişim becerilerini artırma yöntemleri (Yayımlanmamış Yüksek Lisans Tezi). Beykent Üniversitesi, İstanbul.

Kung, H.-Y. (2016). The relationships among parents' socioeconomic status, parental Involvement and academic achievement in Taiwanese middle school students. Journal of Education and Human Development, 5(4), 177-186.

Kurt, U., \& Tas, Y. (2018). The relationships between parental involvement, students' basic psychological needs and students' engagement in science: A path analysis. Journal of Education in Science, Environment and Health (JESEH), 4(2), 183-192.

LaRocque, M., Kleiman, I., \& Darling, S. M. (2011) Parental involvement: the missing link in school achievement. Preventing School Failure: Alternative Education for Children and Youth, 55(3), 115-122.

Lee, J. S., \& Bowen, N. K. (2006). Parent involvement, cultural capital, and the achievement gap among elementary school children. American Educational Research Journal, 43, 193-218.

Lueptow, L. B. (1975). Parental status and influence and the achievement orientations of high school seniors. Sociology of Education, 48(Winter), 91- 110.

Milne, A. M., Myers, D.E., Rosenthal, A. S., \& Ginsburg, A. (1986). Single parents, working mothers, and the educational achievement of school children. Sociology of Education, 59(3), 125-139. 
Niemiec, C. P., Lynch, M. F., Vansteenkiste, J. B., Deci, E. L., \& Ryan, R. M. (2006). The antecedents and consequences of autonomous self-regulation for college: A self-determination theory perspective on socialization. Journal of Adolescence, 29, 761-775.

Özdemir, Y., \& Çok, F. (2011). Ergenlikte özerklik gelişimi. Türk Psikolojik Danışma ve Rehberlik Dergisi, 4(36), 152-164.

Patrikakou, E. N. (2008). The power of parent involvement: Evidence, ideas, and tools for student success. Academic Development Institue.

Pelletier, J., \& Brent, J. M. (2002). Parent participation in children' school readiness: the effects of parental self-efficacy, cultural diversity and teacher strategies, International Journal of Early Childhood, 34(1), 45-60.

Pena, D. C. (2000). Parent involvement: influencing factors and implications. The Journal of Educational Research, 94(1), 42-54.

Poston, D. L., \& Falbo, T. (1990). Academic performance and personality traits of Chinese children: Onlies versus others. American Journal of Sociology, 96(2), 433451 .

Potvin, P., Deslandes, R., \& Leclerc, D. (1999). Family characteristics as predictors of school achievement: parental involvement as a mediator, McGill Journal of Education, 34(2), 135-153.

Reay, D. (2004). Education and cultural capital: The implications of changing trends in education policies. Cultural Trends, 13(50), 73-86.

Robbins, R. J. (1994). An assessment of perceptions of parental autonomy support and control: Child and parent correlates (Unpublished Doctoral Dissertation). University of Rochester, NY.

Shaver, A. V., \& Walls, R. T. (1998). Effect of Title I parent involvement on student reading and mathematics achievement. Journal of Research and Development in Education, 31(2), 90-97.

Sui-Chu, E. H., \& Willms, J.D. (1996). Effects of parental involvement on eight-grade achievement. Sociology of Education, 69(2), 126-141.

Şahin, S., \& Aral, N. (2012). Aile içi iletişim. Ankara Sağllk Bilimleri Dergisi, 1(3), 5566.

Uzun, G. (2017). Akademik başarının okul, aile ve öğrenci özellikleri ile ilişkisinin çok düzeyli yapısal eşitlik modellemesi ile incelenmesi (Yayımlanmamış Doktora Tezi). Ankara Üniversitesi, Ankara.

Vellymalay, S. K. N. (2012). The impact of parent's socioeconomic status on parental involvement at home: A case study on high achievement Indian students of a Tamil school in Malaysia. International Journal of Academic Research in Business and Social Sciences, 2(8), 11-24. 